\title{
The precision study of dual energy X-ray absorptiometry for bone mineral density and body composition measurements in female cynomolgus monkeys
}

\author{
Bin Guo $^{1 \#}$, Qijun Cai ${ }^{1 \#}$, Jinci Mai ${ }^{1}$, Lu Hou ${ }^{1}$, Chunyuan Zeng ${ }^{1}$, Jiefeng Gan ${ }^{1}$, Zhiqiang Tan ${ }^{1}$, Yuefeng Li $^{2}$, \\ Yong Cheng ${ }^{1}$, Jingjie Shang ${ }^{1}$, Yongjin Tang ${ }^{1}$, Xueying Ling ${ }^{1}, J_{i a n}$ Gong ${ }^{1}$, Lu Wang ${ }^{1}$, Hao Xu ${ }^{1}$ \\ ${ }^{1}$ Department of Nuclear Medicine, The First Affiliated Hospital of Jinan University, Guangzhou, China; ${ }^{2}$ Guangdong Landau Biotechnology Co., Ltd., \\ Guangzhou, China
}

Contributions: (I) Conception and design: H Xu, B Guo; (II) Administrative support: J Gong, L Wang; (III) Provision of study materials or patients: Y Li; (IV) Collection and assembly of data: Q Cai, Y Li; (V) Data analysis and interpretation: Q Cai, J Mai; (VI) Manuscript writing: All authors; (VII) Final approval of manuscript: All authors.

"These authors contributed equally to this work.

Correspondence to: Hao Xu, MD, PhD. Department of Nuclear Medicine, The First Affiliated Hospital of Jinan University, Guangzhou 510630, China. Email: txh@jnu.edu.cn.

Background: Dual-energy X-ray absorptiometry (DXA) is a well-accepted tool for monitoring skeletal and body composition changes in biomedical studies. The nonhuman primate model is suitable for studies exploring the pathogenesis of and novel treatments for osteoporosis. Our objectives are to determine the precision of DXA detection in cynomolgus monkeys and to identify the difference in precision in lumbar bone mineral density (BMD) with various segment selections.

Methods: Thirty adult female cynomolgus monkeys underwent duplicate total body DXA scans. Total body bone mineral density $\left(\mathrm{BMD}_{\mathrm{TB}}\right)$ and body composition, including bone mineral content $\left(\mathrm{BMC}_{\mathrm{TB}}\right)$, lean mass $\left(\mathrm{LM}_{\mathrm{TB}}\right)$, and fat mass $\left(\mathrm{FM}_{\mathrm{TB}}\right)$, were analyzed by enCORE software, while lumbar BMD was obtained by manual region-of-interest analysis. The precision was represented as the root-mean-square standard deviation (RMS-SD) and coefficient of variation (RMS-CV\%), and least significant changes (LSCs) were reported.

Results: The RMS-SD (RMS-CV\%) of the repeated DXA analyses for $\mathrm{BMD}_{\mathrm{TB}}, \mathrm{BMC}_{\mathrm{TB}}, \mathrm{LM}_{\mathrm{TB}}$ and $\mathrm{FM}_{\text {Тв }}$ were $0.002 \mathrm{~g} / \mathrm{cm}^{2}(0.50 \%), 0.90 \mathrm{~g}(0.42 \%), 0.015 \mathrm{~kg}(0.49 \%)$, and $0.031 \mathrm{~kg}(2.71 \%)$, respectively. The regional $\mathrm{BMD}$ precision (RMS-CV\%) of the lumbar spine with various combinations ranged from $0.70 \%$ to $1.09 \%$, The LSCs with $80 \%$ statistical confidence $\left(\mathrm{LSC}^{80}\right.$ ) ranged from $1.27 \%$ to $1.97 \%$, and LSC $^{95}$ ranged from $1.94 \%$ to $3.01 \%$.

Conclusions: DXA provided excellent reproducibility in the measurements of BMD and body composition in nonhuman primates. We find DXA reliable for total and regional measurement in skeletal research and the evaluation of osteoporosis treatment with monkeys as animal models.

Keywords: Precision; dual-energy X-ray absorptiometry (DXA); cynomolgus monkeys; bone mineral density (BMD); body composition

Submitted Aug 11, 2021. Accepted for publication Nov 29, 2021.

doi: 10.21037/qims-21-799

View this article at: https://dx.doi.org/10.21037/qims-21-799 


\section{Introduction}

Osteoporosis is a systemic skeletal disease that results in an increased risk of fracture due to a decline in bone density and a deterioration in bone microstructure. In other words, osteoporotic fracture can significantly contribute to a reduction in health-related quality of life and increase economic burden (1). Therefore, it is necessary to understand the role of bone loss and develop new strategies for the prevention and treatment of osteoporosis. Among experimental animal models, nonhuman primates play an important role in the study of osteoporosis due to their close genetic evolutionary relationship to humans and similar physiology, especially their menstrual cycles and natural menopause. Hence, a nonhuman primate model of osteoporosis, typically through ovariectomy (OVX), is extensively used in the research of human skeletal biology and the evaluation of therapies for osteoporosis (2-5).

Quantitative analysis of bone mineral density (BMD) is indispensable in osteoporosis investigations. Among various detection methods, dual-energy $\mathrm{X}$-ray absorptiometry (DXA) is regarded as the "gold standard" for the diagnosis of osteoporosis due to its precision, simple operation and limited radiation risk (6). Additionally, it is also increasingly accepted as a precise and convenient method for body composition assessment (7).

As an attribute of a quantitative measurement technique, precision represents the ability to reproduce the same result in the setting of no real physiological change when the measurement is repeatedly performed with an identical device $(8,9)$. Therefore, precision parameters are crucial for osteoporosis drug discovery to identify the efficacy of a new approach. Both the standard deviation (SD) and coefficient of variation $(\mathrm{CV})$ are representative parameters of precision. Furthermore, the least significant change (LSC), which is the minimum value that indicates real biological change, should also be calculated when considering precision. LSC should be calculated when considering precision (8). The LSC is usually calculated by 15 individuals scanned threetimes each or 10 individuals scanned four times each or 30 individuals scanned twice each.

DXA has been successfully used in macaques for decades and numerous precious studies exist for osteoporosis research (10-12). Previous repeatability studies contrasting DXA with direct physical or chemical analysis of BMD and body composition have been conducted in nonhuman primates $(13,14)$. Black et al. (14) also reported the precision of total body composition, with CV\% values of $10.3 \%, 2.3 \%$ and $1.2 \%$ in fat mass (FM), lean mass (LM) and bone mineral content (BMC), respectively. However, it is recommended by the International Society for Clinical Densitometry (ISCD) using the analysis of precision error for efficacy evaluation of osteoporosis and quality control $(15,16)$. No studies have calculated the LSC value of BMD and other body components in nonhuman primates. Consequently, our objective is to evaluate the reproducibility of DXA measurements according to statistical requirements and then calculate the LSC values. Additionally, we will explore the distinction of reproducibility in different selections of lumbar segments. We present the following article in accordance with the MDAR checklist (available at https:// dx.doi.org/10.21037/qims-21-799).

\section{Methods}

\section{Subjects}

There are 30 out of 33 female cynomolgus macaques (Macaca fascicularis) involved in this study, consisting of 5 young adults ( $4-10$ years), 20 middle-aged adults ( $10-15$ years) and 5 elderly adults ( $>15$ years), which were chosen randomly. The subjects with severely hyperostosis presented obvious bone mass protruding from the edge of the vertebral in DXA scanning and the ones with low FM (2-4\%) were excluded from this study for the affection on the measurements of BMD and body composition. Two of them were excluded for the lack of fat, and one of them was excluded for severely hyperostosis. The animals were supplied by Guangdong Landau Biotechnology Co., Ltd., Guangzhou, China, which possesses Association for Assessment and Accreditation of Laboratory Animal Care (AAALAC) international accreditation. The subjects were fed fruits, a semi-purified diet containing $\sim 1.0 \%$ calcium, $\sim 0.7 \%$ phosphorus and water ad libitum. All subjects were specific pathogen-free (SPF) animals according to national laboratory animal standards. They were housed in groups of 10-15 monkeys consisting of one mature male, several mature females and their progenies in a suitable circumstance. Experiments were performed under a project license (No. LDIACUC2018-0004) granted by the Laboratory Animal Ethics Committee of Guangdong Landau Biotechnology Co., Ltd., in compliance with international AAALAC guidelines for the care and use of animals.

\section{DXA measurements}

All subjects were weighed, and were singly housed at 
Table 1 Characteristics and total BMD and body composition parameters of subjects

\begin{tabular}{lcc}
\hline Parameter & Mean $\pm \mathrm{SD}$ & Range \\
\hline Age (year) & $13.1 \pm 4.3$ & $4.0-19.0$ \\
Weight $(\mathrm{kg})$ & $6.05 \pm 1.47$ & $3.60-9.10$ \\
Crown rump length $(\mathrm{cm})$ & $43.63 \pm 3.75$ & $33.0-55.0$ \\
Bone area $\left(\mathrm{cm}^{2}\right)$ & $0.454 \pm 0.037$ & $0.388-0.540$ \\
$\mathrm{BMD}_{\text {ТВ }}\left(\mathrm{g} / \mathrm{cm}^{2}\right)$ & $0.499 \pm 0.053$ & $0.395-0.624$ \\
$\mathrm{BMC}_{\text {ТВ }}(\mathrm{g})$ & $227.96 \pm 37.41$ & $158.50-308.80$ \\
$\mathrm{LM}_{\text {ТВ }}(\mathrm{kg})$ & $3.327 \pm 0.451$ & $4.330-2.496$ \\
$\mathrm{FM}_{\text {ТВ }}(\mathrm{kg})$ & $2.037 \pm 1.159$ & $0.118-4.422$ \\
\hline
\end{tabular}

$\mathrm{BMD}$, bone mineral density; $\mathrm{SD}$, standard deviation; $\mathrm{BMD}_{\mathrm{TB}}$, total body bone mineral density; $\mathrm{BMC}_{\mathrm{TB}}$, total body bone mineral content; $\mathrm{LM}_{\mathrm{TB}}$, total body lean mass; $\mathrm{FM}_{\mathrm{TB}}$, total body fat mass.

least $24 \mathrm{~h}$ before DXA scans. After an overnight fast, the animals were anesthetized using ketamine hydrochloride $(5-10 \mathrm{mg} / \mathrm{kg}$, i.m.) and $3 \%$ pentobarbital sodium $(0.5-1 \mathrm{~mL} / \mathrm{kg}$, i.v.). Additional chemical suppression was provided using pentobarbital sodium with less than $1 / 3$ of the integral dose when necessary. Crown rump length were measured using tapeline before DXA scanning.

Total body DXA scans were performed using GE Lunar iDXA (GE Healthcare, Madison, WI, USA). Daily quality assurance scans were conducted by scanning an aluminum spine phantom according to the manufacturer's instructions. Within a 2-month period, all animals were tested twice immediately after on another in the anteroposterior (AP) position with repositioning before the second scan. Total body composition, including $\mathrm{BMC}_{\mathrm{TB}}, \mathrm{LM}_{\mathrm{TB}}$, and $\mathrm{FM}_{\mathrm{TB}}$, was automatically analyzed by enCORE software (version 16.0, small animal mode, GE Healthcare), while BMD at the lumbar spine was based on three replicate assays with manual delineation of regions of interest (ROIs). After each scan, in order to reduce the random error caused by manual delineation for ROIs determination at the lumbar spine, three replicate assays were executed and the average value of them were represented as ultimate value about the BMD parameters. All DXA measurements and analyses were performed by a well-trained operator throughout the study.

\section{Analysis}

Short-term precision is equivalent to the RMS of SD or $\mathrm{CV} \%$, which were represented as follows (8):

$$
\begin{aligned}
& C V \%_{R M S}=\sqrt{\frac{\sum_{i=1}^{m}\left(C V \%^{2}\right)}{m}} \\
& S D_{R M S}=\sqrt{\frac{\sum_{i=1}^{m}\left(S D^{2}\right)}{m}}
\end{aligned}
$$

where $\mathrm{m}$ is the number of samples.

The formula of LSC is as follows:

$$
L S C=Z^{\prime}(\operatorname{Pr}) \sqrt{\frac{1}{n_{1}}+\frac{1}{n_{2}}}
$$

in which $Z^{\prime}$ is based on the statistical confidence level, $\operatorname{Pr}$ is the precision value, either root-mean-square SD (RMS-SD) or root mean square CV (RMS-CV\%), $\mathrm{n}_{1}$ is the number of first measurements, and $n_{2}$ is the number of follow-up measurements.

Precision values were represented as RMS-SD and RMS-CV\%, while the descriptive data were reported as the mean and SD (mean $\pm \mathrm{SD})$. LCS with the basis of RMSSD and RMS-CV\% are demonstrated with $80 \%$ and $95 \%$ confidence intervals (CIs). All data analysis was performed by Microsoft Excel 2016 (Microsoft, Inc., Redmond, WA, USA).

\section{Results}

The tested monkeys ranged in age from 4 to 19 years $(n=30$, $13.1 \pm 4.3$ years), and mean weight was $6.05 \pm 1.47 \mathrm{~kg}$. The crown rump length was $43.63 \pm 3.75 \mathrm{~cm}$. The characteristic and descriptive data of subjects' body composition are presented in Table 1. Although the lumbar spine of most monkeys consists of 7 vertebrae, 8 in 30 (26.7\%) only present 6 segments. In the subjects with fewer lumbar vertebrae, we counted the sequence from the bottom up to last thoracic.

In total body composition, the largest value of RMS$\mathrm{CV} \%$ was $2.71 \%$ in $\mathrm{FM}$, while the values of BMD and $\mathrm{LM}$ were both no more than $0.5 \%$. Additionally, the RMS$\mathrm{SD}, \mathrm{LSC}^{80}$ and $\mathrm{LSC}^{95}$ in different total body components are shown in Table 2. Excluding the last lumbar vertebra, all possible combinations of successive spinal segments were outlined manually, presenting various precisions with RMS-CV\% ranging from $0.70 \%$ to $1.09 \%$, and then the $\mathrm{LSC}^{80}$ and $\mathrm{LSC}^{95}$ ranged from $1.27 \%$ to $1.97 \%$ and from $1.94 \%$ to $3.01 \%$, respectively. The RMS-SD ranged from 
Table 2 Short-term precision values of total body BMD and composition

\begin{tabular}{|c|c|c|c|c|c|c|}
\hline Parameter & RMS-SD & RMS-CV\% & \multicolumn{2}{|c|}{${ }_{1 \times 1} \mathrm{LSC}^{80}$} & \multicolumn{2}{|c|}{${ }_{1 \times 1} \mathrm{LSC}^{95}$} \\
\hline $\mathrm{BMD}_{\text {TВ }}$ & 0.002 & 0.50 & 0.004 & 0.91 & 0.006 & 1.39 \\
\hline $\mathrm{BMC}_{\mathrm{TB}}$ & 0.90 & 0.42 & 1.63 & 0.76 & 2.49 & 1.16 \\
\hline $\mathrm{LM}_{\mathrm{TB}}$ & 0.015 & 0.49 & 0.027 & 0.89 & 0.042 & 1.36 \\
\hline
\end{tabular}

BMD, bone mineral density; RMS-SD, root mean square standard deviation; RMS-CV\%, root mean square coefficient of variation; ${ }_{1 \times 1} \mathrm{LSC}^{80}$, least significant changes for one scan at baseline and one at follow-up at $80 \%$ confidence; ${ }_{1 \times 1} \mathrm{LSC}^{95}$, least significant changes for one scan at baseline and one at follow-up at $95 \%$ confidence; $\mathrm{BMD}_{\mathrm{TB}}$, total body bone mineral density; $\mathrm{BMC}_{\mathrm{TB}}$, total body bone mineral content; $\mathrm{LM}_{\mathrm{TB}}$, total body lean mass; $\mathrm{FM}_{\mathrm{TB}}$, total body fat mass.

Table 3 Short-term precision values of the lumbar spine in different combinations

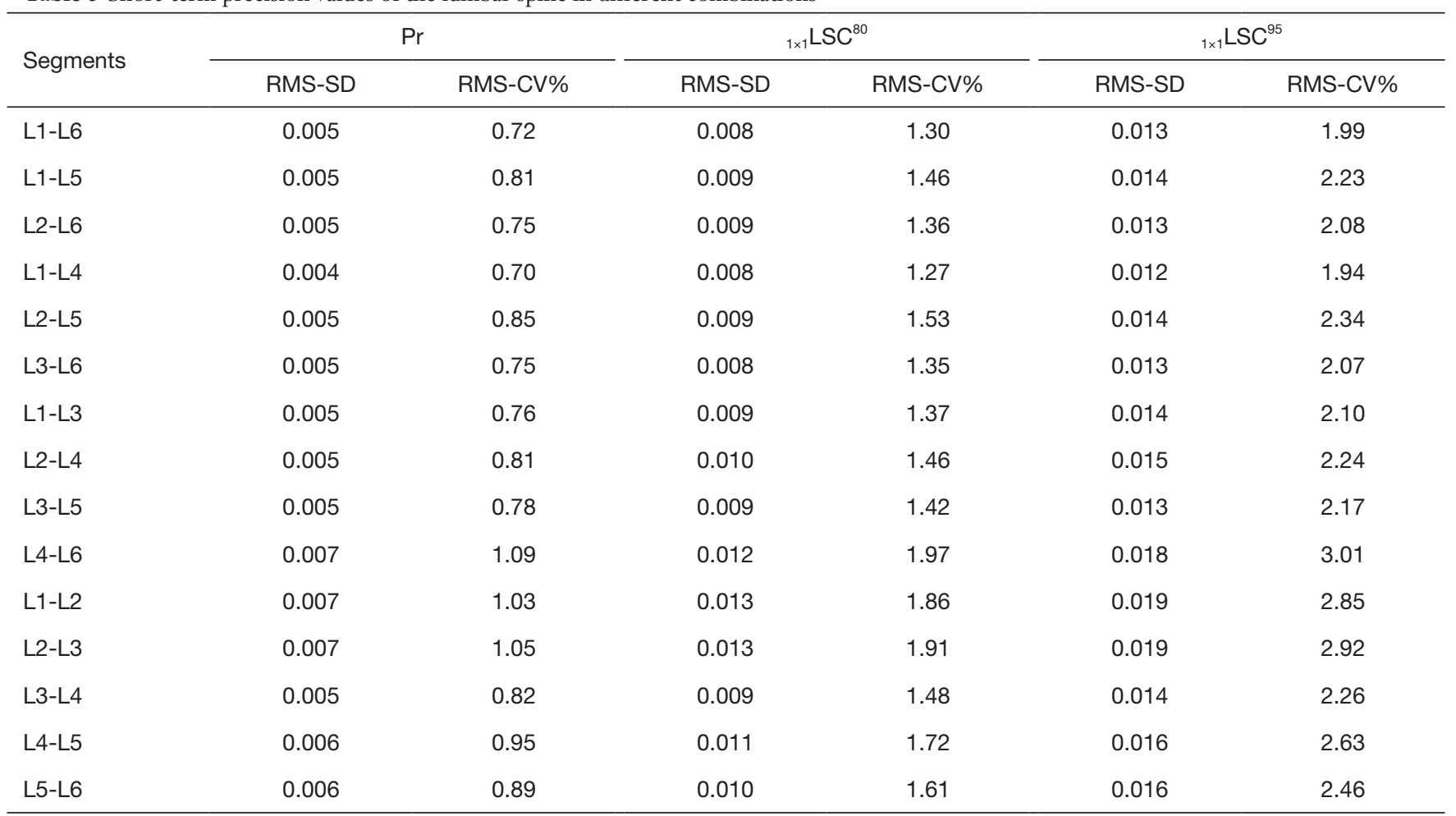

Pr, precision; ${ }_{1 \times 1} \mathrm{LSC}^{80}$, least significant changes for one scan at baseline and one at follow-up at $80 \%$ confidence; ${ }_{1 \times 1} \mathrm{LSC}{ }^{95}$, least significant changes for one scan at baseline and one at follow-up at 95\% confidence; RMS-SD, root mean square of standard deviation; RMS-CV\%, root mean square of coefficient of variation.

0.004 to $0.007 \mathrm{~g} / \mathrm{cm}^{2}$, with $\mathrm{LSC}^{80}$ and $\mathrm{LSC}^{95}$ ranging from 0.008 to $0.013 \mathrm{~g} / \mathrm{cm}^{2}$ and from 0.012 to $0.019 \mathrm{~g} / \mathrm{cm}^{2}$, respectively, which are shown in Table 3.

\section{Discussion}

In this study, we demonstrated the short-term precision of BMD and body composition measurements using GE Lunar iDXA in 30 female cynomolgus monkeys. It showed excellent performance in detecting $\mathrm{BMD}_{\mathrm{TB}}, \mathrm{BMC}_{\mathrm{TB}}$ and $\mathrm{LM}_{\mathrm{TB}}$ with $\mathrm{RMS}-\mathrm{CV} \%$ values lower than $0.5 \%$; nevertheless, a larger variation was observed in $\mathrm{FM}_{\mathrm{TB}}$ with RMS-CV\% $2.71 \%$. In comparing the reproducibility of different spine segment combinations, all conformed to the 
minimum acceptable precision of $1.9 \%$ for the lumbar spine, according to the Adult Official Positions of the ISCD (17).

The RMS-CV\% in total body composition was slightly less than that detected in previous studies $(14,18,19)$, possibly because the analysis software applied in our study was specifically designed for small animals rather than pediatric software, resulting in better repeatability. Our subjects' weight range fits the recommended weight $(2-20 \mathrm{~kg})$ of the medium scan mode used in the present research, while the recommended weight $(15-25 \mathrm{~kg})$ in pediatric software was not as suitable for nonhuman primates in Black et al.'s study (14).

To distinguish real biological change from error inherent in the test itself, LSC is raised to represent the smallest change beyond the range of error. To our knowledge, no studies have calculated the LSC value of BMD and other body components in nonhuman primates. In general, LSC must be calculated with $95 \%$ statistical confidence under ideal conditions, but $80 \%$ statistical confidence is more than adequate for clinical decisions (8). Hence, both LSC $^{80}$ and $\mathrm{LSC}^{95}$ of RMS-CV\% in different body components are presented.

There is no consensus in the selection of vertebral segments in studies of skeletal changes in nonhuman primates, although the combination of L2-L4 is the most popular selection (20-23). To determine the precision of different combinations, we first calculated the precision error of all possibilities based on manual delineation of ROIs, excluding L7 to avoid interference of the pelvis. As shown in Table 3, the greatest precision is shown in L1-L4 with $\mathrm{RMS}-\mathrm{CV} \% 0.70 \%$, while the largest variation is in L4-L6 with RMS-CV\% 1.09\%, which completely conforms with the acceptable precision of $1.9 \%\left(\mathrm{LSC}^{95}=5.3 \%\right.$ ) recommended by the ISCD guidelines (17). In other words, there was no significant difference in precision in terms of the lumbar spine option. L2-L4 performs fairly well, with an RMS-CV\% of $0.81 \%$. To prevent disturbance of the ribs and ilium, we recommend excluding L1 and L7 from the selection.

Due to large economical burden caused by osteoporotic fracture, researches referring to novel strategies for the prevention and treatment of osteoporosis are increasing. OVX cynomolgus monkey is in common use as nonhuman primate model of osteoporosis (10-12). It will be better to introduce the precision data, like LSC, in these studies to evaluate the efficacy of new agents targeting osteoporosis. The main limitation of our study is that the repeatability data of spine BMD were acquired manually, which may increase precision error. Nevertheless, to some extent, the variability could be restricted with replicate assays.

\section{Conclusions}

Analysis software in a small animal model could improve the ability to precisely monitor bone mass and body composition between repeated scans in cynomolgus monkeys. Diverse choices of vertebral segments may not influence the precision of lumbar spine BMD; all combinations meet the standard of reproducibility according to ISCD guidelines. With excellent precision, DXA is suitable for nonhuman primates studies in terms of BMD and body composition, such as exploring the pathogenetic mechanism and evaluating novel therapies for osteoporosis.

\section{Acknowledgments}

Funding: This study was financially supported by the National Natural Science Foundation of China (81871383).

\section{Footnote}

Reporting Checklist: The authors have completed the MDAR checklist. Available at https://dx.doi.org/10.21037/qims-21799

Conflicts of Interest: All authors have completed the ICMJE uniform disclosure form (available at https://dx.doi. org/10.21037/qims-21-799). YL is the head of Research and Development Department in Guangdong Landau Biotechnology Co. Ltd. The other authors have no conflicts of interest to declare.

Ethical Statement: The authors are accountable for all aspects of the work in ensuring that questions related to the accuracy or integrity of any part of the work are appropriately investigated and resolved. Experiments were performed under a project license (No. LDIACUC2018-0004) granted by the Laboratory Animal Ethics Committee of Guangdong Landau Biotechnology Co., Ltd., in compliance with international AAALAC guidelines for the care and use of animals.

Open Access Statement: This is an Open Access article distributed in accordance with the Creative Commons Attribution-NonCommercial-NoDerivs 4.0 International 
License (CC BY-NC-ND 4.0), which permits the noncommercial replication and distribution of the article with the strict proviso that no changes or edits are made and the original work is properly cited (including links to both the formal publication through the relevant DOI and the license). See: https://creativecommons.org/licenses/by-nc-nd/4.0/.

\section{References}

1. Cummings SR, Melton LJ. Epidemiology and outcomes of osteoporotic fractures. Lancet 2002;359:1761-7.

2. Smith SY, Jolette J, Turner CH. Skeletal health: primate model of postmenopausal osteoporosis. Am J Primatol 2009;71:752-65

3. Ominsky MS, Boyd SK, Varela A, Jolette J, Felx M, Doyle N, Mellal N, Smith SY, Locher K, Buntich S, Pyrah I, Boyce RW. Romosozumab Improves Bone Mass and Strength While Maintaining Bone Quality in Ovariectomized Cynomolgus Monkeys. J Bone Miner Res 2017;32:788-801.

4. Doyle N, Varela A, Haile S, Guldberg R, Kostenuik PJ, Ominsky MS, Smith SY, Hattersley G. Abaloparatide, a novel PTH receptor agonist, increased bone mass and strength in ovariectomized cynomolgus monkeys by increasing bone formation without increasing bone resorption. Osteoporos Int 2018;29:685-97.

5. Yamada H, Ochi Y, Mori H, Nishikawa S, Hashimoto Y, Nakanishi Y, Tanaka M, Bruce M, Deacon S, Kawabata K. Effects of 16-month treatment with the cathepsin K inhibitor ONO-5334 on bone markers, mineral density, strength and histomorphometry in ovariectomized cynomolgus monkeys. Bone 2016;86:43-52.

6. Cheng X, Yuan H, Cheng J, Weng X, Xu H, Gao J, Huang M, Wáng YXJ, Wu Y, Xu W, Liu L, Liu H, Huang C, Jin Z, Tian W; Bone and Joint Group of Chinese Society of Radiology, Chinese Medical Association (CMA), Musculoskeletal Radiology Society of Chinese Medical Doctors Association, Osteoporosis Group of Chinese Orthopedic Association, Bone Density Group of Chinese Society of Imaging Technology, CMA*. Chinese expert consensus on the diagnosis of osteoporosis by imaging and bone mineral density. Quant Imaging Med Surg 2020;10:2066-77.

7. Andreoli A, Scalzo G, Masala S, Tarantino U, Guglielmi G. Body composition assessment by dual-energy X-ray absorptiometry (DXA). Radiol Med 2009;114:286-300.

8. Bonnick SL, Johnston CC Jr, Kleerekoper M, Lindsay R, Miller P, Sherwood L, Siris E. Importance of precision in bone density measurements. J Clin Densitom 2001;4:105-10.

9. Glüer CC, Blake G, Lu Y, Blunt BA, Jergas M, Genant HK. Accurate assessment of precision errors: how to measure the reproducibility of bone densitometry techniques. Osteoporos Int 1995;5:262-70.

10. Yamada H, Ochi Y, Mori H, Nishikawa S, Hashimoto Y, Nakanishi Y, Tanaka M, Bruce M, Deacon S, Kawabata $\mathrm{K}$. Effects of 16-month treatment with the cathepsin $\mathrm{K}$ inhibitor ONO-5334 on bone markers, mineral density, strength and histomorphometry in ovariectomized cynomolgus monkeys. Bone 2016;86:43-52.

11. Mashiba T, Saito M, Yamagami Y, Tanaka M, Iwata K, Yamamoto T. Effects of suppressed bone remodeling by minodronic acid and alendronate on bone mass, microdamage accumulation, collagen crosslinks and bone mechanical properties in the lumbar vertebra of ovariectomized cynomolgus monkeys. Bone 2017;97:184-91.

12. Doyle N, Varela A, Haile S, Guldberg R, Kostenuik PJ, Ominsky MS, Smith SY, Hattersley G. Abaloparatide, a novel PTH receptor agonist, increased bone mass and strength in ovariectomized cynomolgus monkeys by increasing bone formation without increasing bone resorption. Osteoporos Int 2018;29:685-97.

13. Jayo MJ, Rankin SE, Weaver DS, Carlson CS, Clarkson TB. Accuracy and precision of lumbar bone mineral content by dual-energy X-ray absorptiometry in live female monkeys. Calcif Tissue Int 1991;49:438-40.

14. Black A, Tilmont EM, Baer DJ, Rumpler WV, Ingram DK, Roth GS, Lane MA. Accuracy and precision of dual-energy $\mathrm{X}$-ray absorptiometry for body composition measurements in rhesus monkeys. J Med Primatol 2001;30:94-9.

15. Baim S, Wilson CR, Lewiecki EM, Luckey MM, Downs RW Jr, Lentle BC. Precision assessment and radiation safety for dual-energy $\mathrm{X}$-ray absorptiometry: position paper of the International Society for Clinical Densitometry. J Clin Densitom 2005;8:371-8.

16. Morgan SL, Prater GL. Quality in dual-energy X-ray absorptiometry scans. Bone 2017;104:13-28.

17. The International Society For Clinical Densitometry. Precision Assessment. Available online: https://iscd.org/ learn/official-positions/adult-positions/

18. Champ JE, Binkley N, Havighurst T, Colman RJ, Kemnitz JW, Roecker EB. The effect of advancing age on bone mineral content of female rhesus monkeys. Bone 1996;19:485-92.

19. Chen Y, Shimizu M, Sato K, Koto M, Tsunemi K, Yoshida 
T, Yoshikawa Y. Effects of aging on bone mineral content and bone biomarkers in female cynomolgus monkeys. Exp Anim 2000;49:163-70.

20. Jayo MJ, Jerome CP, Lees CJ, Rankin SE, Weaver DS. Bone mass in female cynomolgus macaques: a crosssectional and longitudinal study by age. Calcif Tissue Int 1994;54:231-6.

21. Colman RJ, Kemnitz JW, Lane MA, Abbott DH, Binkley N. Skeletal effects of aging and menopausal status in female rhesus macaques. J Clin Endocrinol Metab

Cite this article as: Guo B, Cai Q, Mai J, Hou L, Zeng C, Gan J, Tan Z, Li Y, Cheng Y, Shang J, Tang Y, Ling X, Gong J, Wang L, Xu H. The precision study of dual energy X-ray absorptiometry for bone mineral density and body composition measurements in female cynomolgus monkeys. Quant Imaging Med Surg 2022;12(3):2051-2057. doi: 10.21037/qims-21-799
1999;84:4144-8.

22. Black A, Tilmont EM, Handy AM, Scott WW, Shapses SA, Ingram DK, Roth GS, Lane MA. A nonhuman primate model of age-related bone loss: a longitudinal study in male and premenopausal female rhesus monkeys. Bone 2001;28:295-302.

23. Havill LM, Mahaney MC, Czerwinski SA, Carey KD, Rice $\mathrm{K}$, Rogers J. Bone mineral density reference standards in adult baboons (Papio hamadryas) by sex and age. Bone 2003;33:877-88. 